\title{
Bioactivity of Visual Pigments with Sterically Modified Retinal Analogs
}

\author{
Elena Karnaukhova, Shuanghua Hu, Romsai Boonyasai, Qiang Tan, ${ }^{1}$ \\ and Koji Nakanishi ${ }^{2}$
}

Department of Chemistry, Columbia University, New York, New York 10027

Received December 23, 1998

\begin{abstract}
Studies of several retinal analogs and the rhodopsin pigments incorporating them, lead to further clarification of the structural requirement of the retinal chromophore in the photoactivation process of rhodopsin. The data with a pigment incorporating an acyclic retinal show that the cyclohexene moiety is not required for formation of a stable pigment, which, however, has a reduced photoactivity. Our data also show that extra methyl groups at 13- and 14-positions of 11-cis retinal reduce the rate of retinal binding, photoactivity, and stability of the pigments. These data, taken together, give rise to a clear picture about the binding environment of the retinal chromophore and how retinal interacts with and activates the protein following its photoisomerization. The opsin/11-cis retinal complex has evolved into an ideal system, which is capable of converting photoenergy into Meta-II formation with high efficiency, critical for visual transduction. (c) 1999 Academic Press
\end{abstract}

Key Words: synthetic retinals; rhodopsin; phosphodiesterase assay; photoactivity.

\section{INTRODUCTION}

Bovine rhodopsin (1), $\lambda_{\max } 500 \mathrm{~nm}$, the best studied of the visual pigments because of its availability in large quantities, was the first to be sequenced (2-4). Its single polypeptide chain consists of 348 amino acid residues arranged into seven transmembrane $\alpha$-helices. An 11-cis retinal chromophore is linked to the terminal amino group of Lys 296 via a protonated Schiff base. The light-induced primary photochemical event, retinal 11-cis to all-trans isomerization (5-7), triggers a series of protein conformational changes driven by retinal-protein interaction, resulting in the deprotonation of the Schiff base to yield metarhodopsin II (Meta-II), $\lambda_{\max } 380 \mathrm{~nm}(8-12)$. Meta-II, the active form of rhodopsin, binds and activates the G-protein transducin, thus initiating the enzymatic cascade of the visual transduction process. Transducin activates phosphodiesterase, which in turn catalyzes the hydrolysis of cGMP.

${ }^{1}$ Current address: Sloan-Kettering Institute for Cancer Research, Memorial Sloan-Kettering Cancer Center, 1275 York Avenue, New York, NY 10028.

${ }^{2}$ To whom correspondence and reprint requests should be addressed. Fax: (212) 932-8273. E-mail: kn5@columbia.edu. 
Despite the progress in our understanding of biochemical events of visual transduction, the rhodopsin structure and molecular mechanism of rhodopsin activation triggered by 11-cis-retinal isomerization is still obscure. In the dark static state, the chromophoric ionone ring is close to $\operatorname{Trp} 265$ in the middle of helix $\mathrm{F}$ (13), showing that the chromophore lies near the center of the lipid bilayer with its polyene sidechain roughly horizontal to the membrane plane. Recent CD results have also indicated that the absolute sense of twist around the 12-s-bond is negative (14) (see Figs. 3 and 5). Examination of photochemical properties and enzymatic activities of 11-cis locked rhodopsin analogs $(15-19)$ have demonstrated that activation by light requires complete 11-cis to all-trans isomerization with full involvement of retinal-receptor interactions.

The retinal chromophore with its trimethyl cyclohexene moiety, methylated polyene chain, nonplanar 6-s-cis and 12-s-trans bonds, unstable 11-cis geometry, and protonated Schiff base (PSB) linkage formed with Lys-296 is ideally suited for visual transduction and wavelength regulation (20). Examination of the biochemistry of pigments incorporating several retinal analogs has clarified further structural aspects of the chromophore with respect to the rhodopsin function. Our data below show that although the cyclohexene ring is not required for retinal binding to form a stable pigment, its interaction with the protein enhances the efficiency of the retinal photoisomerization and the protein activation. On the other hand, introduction of extra alkyl groups at 13- and 14-positions of 11-cis retinal reduces the rate of retinal incorporation into rhodopsin, the stability of the chromophore, and photoactivation of the pigments.

\section{MATERIALS AND METHODS}

\section{General}

Fresh bovine retinae were purchased from J. A. Lawson Co. (Lincoln, NE) and stored frozen at $-70^{\circ} \mathrm{C}$. ATP, ADP, dithiothreitol (DTT), Concanavalin A-Sepharose 4B, methyl $\alpha$-D-mannopyranoside, protease inhibitors, 1- $\alpha$-phosphatidylethanolamine (PE) from bovine brain, 4-(2-hydroxyethyl)-1-piperazine-ethane-sulfonic acid (Hepes), 3-[(3-Cholamidopropyl)dimethylamino]-2-hydroxy-1-propanesulfonate (Chapso), phenylmethanesulfonyl fluoride (PMSF), and digitonin were purchased from Sigma. Other chemicals were purchased from Aldrich.

\section{Preparation and Purification of 11-cis-retinal Analogs}

Acyclic retinal 2 was prepared via two- and five-carbon extension reactions from the acyclic $\beta$-ionone analog obtained from aldol condensation of 2-isopropyl-3-methyl-2crotonaldehyde with acetone (21). 14-Methyl retinal $\mathbf{3}$ and 13-ethyl retinal $\mathbf{4}$ were synthesized as described $(22,23)$. After HPLC purification, the all-trans retinals were dissolved in acetonitrile $(1 \mathrm{mg} / \mathrm{ml})$ and irradiated for $2-3 \mathrm{~h}$ at $0^{\circ} \mathrm{C}$ by a $500 \mathrm{~W}$ Sylvania tungsten lamp with a 430-nm cut-off filter. The 11-cis isomers were isolated by semiprep YMC Silicagel HPLC $(250 \times 5 \mathrm{~mm}$, SIL) using $5 \%$ ethyl acetate in hexane, isocratic elution, and their structures were confirmed by NMR.

\section{Preparation of Visual Pigments and Enzymes}

Bovine Rod Outer Segment (ROS) were isolated from 200 frozen retinae by the flotation method $(15,24)$ in sucrose solution prepared from isotonic buffer A 
(10 mM Tris, $60 \mathrm{mM} \mathrm{KCl}, 30 \mathrm{mM} \mathrm{NaCl}, 2 \mathrm{mM} \mathrm{MgCl}_{2}, 0.1 \mathrm{mM}$ PMSF, $1 \mathrm{mM}$ DTT, pH 8.0). The enzymes were extracted twice by hypotonic buffer B: $10 \mathrm{mM}$ Tris, $\mathrm{pH} 8.0,2 \mathrm{mM}$ EDTA, $2 \mathrm{mM}$ dithiothreitol, $2 \mathrm{mg}$ each of soybean trypsin inhibitors, aprotinin, benzamidine, leupeptin, and pepstatin A in $100 \mathrm{ml}$ buffer. The stripped ROS and the enzyme extract thus obtained were further concentrated for bioassay. The stripped ROS can be stored at $-70^{\circ} \mathrm{C}$ for future use. Bleaching of ROS was performed in hypotonic Hepes buffer ( $\mathrm{pH} 7.0$ ) containing $100 \mathrm{mM}$ hydroxylamine on ice-bath under day light for $4 \mathrm{~h}$. Excess hydroxylamine was removed through five washings with $40 \mathrm{ml}$ each of buffer B. For qualitative preparation of rhodopsin analogs for phosphodiesterase assay and CD measurements, freshly prepared opsin was suspended (ca. $3 \mathrm{OD} / \mathrm{ml}$ ) in $10 \mathrm{mM}$ Hepes buffer $\mathrm{C}$ (10 mM Hepes, $50 \mathrm{mM}$ DTPA, $0.1 \mathrm{mM}$ PMSF, $1 \mathrm{mM}$ DTT, pH 7.5), and this was treated with 2 OD equivalents of retinal dissolved in a small amount of ethanol $(<2 \% \mathrm{v} / \mathrm{v})$. In case of acyclic retinal, the mixture was incubated in the dark at room temperature and stirred overnight. For 14-methyl retinal (3) and 13ethyl retinal (4), a 10 -h incubation at $37^{\circ} \mathrm{C}$ was required. As a control, native rhodopsin was regenerated under the same conditions. To obtain pigments for spectroscopic measurement and stability studies, the regenerated pigments in Hepes buffer were spun down at $45,000 \mathrm{rpm}, 30 \mathrm{~min}$, and solubilized in $2 \%$ digitonin, followed by purification on a Concanavalin A-Sepharose gel column at $4{ }^{\circ} \mathrm{C}$ under dim red light as described (25). The binding rate was estimated from the increment of the pigment absorption around $500 \mathrm{~nm}(26)$.

\section{UV/VIS and CD Measurement}

UV/Vis spectra of the pigments were recorded on a Perkin-Elmer Lambda 6B UV/Vis spectrophotometer. CD measurements were performed on a JASCO J-720 spectropolarimeter from 250 to $600 \mathrm{~nm}, 1 \mathrm{~cm}$ cell; an average of four scans were performed rapidly per measurement to decrease the possible bleaching of rhodopsin samples by the measuring light. The concentration of the rhodopsin analog samples was adjusted to $0.4 \mathrm{OD} / \mathrm{ml}$. The pigment spectra were obtained by subtracting the bleached ROS spectra as a baseline.

\section{Quantum Efficiency Measurements}

Quantum efficiency measurements (27) were performed by monitoring the bleaching of purified pigments under irradiation, each for 1-3 min, total time of bleaching $30 \mathrm{~min}$. The samples in cuvettes, $0.2 \mathrm{OD} / \mathrm{ml}$ and containing $10 \mathrm{mM}$ $\mathrm{NH}_{2} \mathrm{OH}$, were irradiated by a $160 \mathrm{~W}$ Sylvania tungsten halogen lamp stabilized by a $250 \mathrm{~W}$ SOLA constant voltage transformer. The dynamics of bleaching was recorded using a Perkin-Elmer IF 320 UV/Vis spectrophotometer. The irradiation light was filtered by a $530 \pm 10-\mathrm{nm}$ interference filter and controlled by a shutter and built-in mirror, which was mounted at $45^{\circ}$ with respect to both measuring light and irradiation light. The slopes of the plot of $-\log \left(10^{\mathrm{At}}-1\right)$ against total irradiation time were directly proportional to the photosensitivity of the pigments. Quantum efficiency of the pigments was calculated from the known quantum 
efficiency of rhodopsin (0.67) (28) and the molar extinction coefficient of the corresponding pigments.

\section{Phosphodiesterase Assay}

Phosphodiesterase assay was performed according to the protocol developed by Liebman and Ivanczsuk (29) under dim red light with some modifications described below. The pigment $(80 \mu \mathrm{M} / \mathrm{ml}$ in $10 \mathrm{mM}$ Hepes buffer) was mixed with isotonic buffer D (10 mM Hepes, $60 \mathrm{mM} \mathrm{KCl}, 30 \mathrm{mM} \mathrm{NaCl}, 2 \mathrm{mM} \mathrm{MgCl}, 0.1 \mathrm{mM}$ PMSF, $1 \mathrm{mM}$ DTT, $\mathrm{pH} 8.0$ ) to give a final concentration of $6 \mathrm{mM} / \mathrm{ml}$. The suspension was then treated with 1.2 equivalent of enzyme extract, usually 10-30 $\mu$ l, depending on the final volume of the concentrated enzyme extract and the total amount of ROS used for extraction. After incubation for $10 \mathrm{~min}$ at room temperature, GTP was added and $\mathrm{pH}$ of the mixture was adjusted to $8.00 \pm 0.05$ by $1 \mathrm{M} \mathrm{KOH}$ solution. After addition of cGMP the mixture was monitored for $0.5 \mathrm{~min}$ to check the level of dark activity using a Sensorex S900c fast $\mathrm{pH}$ electrode coupled through an Orion $811 \mathrm{pH}$ meter to a Servo Chessell 321 chart recorder. After exposure of the mixture to a suitably attenuated flash of light, Xenon flash-Metz-Mecablitz 45 CL, the lightinduced phosphodiesterase activity or light activity was monitored for 1-2 min. For these measurements, $10 \mathrm{mM}$ GDP, $10 \mathrm{mM}$ GTP, and $50 \mathrm{mM}$ cGMP stock solutions in isotonic Hepes buffer prepared in 1- to 2-ml aliquots were used. The flash bleached about $20 \%$ of rhodopsin under bioassay conditions. The intensity of light was attenuated to $25,2.5,0.625$, and $0.25 \%$ by combination of neutral density filters, Kodak $0.6,1$, and 2 ND. The conversion factor between $\mathrm{pH}$ change and the proton released was obtained by $\mathrm{HCl}$ titration of a mixture of $900 \mu \mathrm{l}$ of the isotonic buffer and 100 $\mu$ hypotonic buffer, $\mathrm{pH} 8.0$, which corresponded to buffer components of the bioassay mixture. The conversion factor $\Delta \mathrm{pH} / \Delta \mathrm{mM} \mathrm{HCl}$ was $0.162 \mathrm{mM}^{-1}$. The curves of $\mathrm{pH}$ versus time were converted to cGMP hydrolyzed versus time.

\section{RESULTS}

\section{Binding of Retinal Analogs with Apoprotein}

Acyclic retinal 2, 14-methylretinal 3, and 13-ethylretinal 4 bind to opsin to form acyclic Rh, 13-Et-Rh, and 14-Me-Rh, respectively, the UV/Vis spectra of which are shown in Fig. 2. The binding of retinals is much faster in $10 \mathrm{mM}$ Hepes than in isotonic buffer. In $10 \mathrm{mM}$ Hepes buffer the binding of acyclic retinal 2 was over within $10 \mathrm{~min}$, while in isotonic buffer at $10^{\circ} \mathrm{C}$, the binding of 2 and 11 -cis retinal 1 required, respectively, 10 and $30 \mathrm{~h}$. The rapid binding of acyclic 2 should be noted because there appears to be no report of a synthetic retinal analog having a higher binding rate than 11-cis retinal.

14-Methylretinal 3 and 13-ethylretinal 4 bind to opsin much slower than 11-cis retinal. At $37^{\circ} \mathrm{C}$ in $10 \mathrm{mM}$ Hepes, the regeneration was complete in 3 and $1 \mathrm{~h}$, respectively, for 3 and 4 , while at $25^{\circ} \mathrm{C}$, both required a 24-h regeneration period. Thus the extra alkyl groups in 14-methylretinal $\mathbf{3}$ and 13-ethylretinal $\mathbf{4}$ hinder the 11-cis retinal from entering the binding cavity.

\section{Spectra of the Pigments}

The retinal chromophore in rhodopsin, $\lambda_{\max } 498 \mathrm{~nm}$, shows strong positive CD Cotton effects at 490 ( $\alpha$-band) and $340 \mathrm{~nm}$ ( $\beta$-band) (Fig. 3a, curve 2$)$. The observed 
<smiles>CC1=C(/C=C/C(C)=C/C=C\C(C)=C\C=O)C(C)(C)CCC1</smiles><smiles>CC(C)=C(/C=C/C(C)=C/C=C\C(C)=C\C=O)C(C)C</smiles><smiles>CC1=C(/C=C/C(C)=C/C=C\C(C)=C(/C)C=O)C(C)(C)CCC1</smiles><smiles>CCC(/C=C\C=C(C)\C=C\C1=C(C)CCCC1(C)C)=C\C=O</smiles><smiles>CC1=C(/C=C/C(C)=C2/C=C/C(=C/C=O)CC2)C(C)(C)CC(=[W])C1=O</smiles><smiles>CC(/C=C\C=C(C)\C=C\c1ccc(C2(C(F)(F)F)N=N2)cc1)=C\C=O</smiles>

FIG. 1. Structures of 11-cis retinal and its analogs.

chirality can be attributed to the intrinsic asymmetry of the chromophore induced by the protein chiral environment. As shown in Fig. 3b, the 11-cis chromophore is twisted around the 6-s and 12-s bonds due to the steric interaction between 5-Me and 8- $\mathrm{H}$, and negatively twisted between $13-\mathrm{Me}$ and $10-\mathrm{H}(14,17,30,31)$. Ito and coworkers

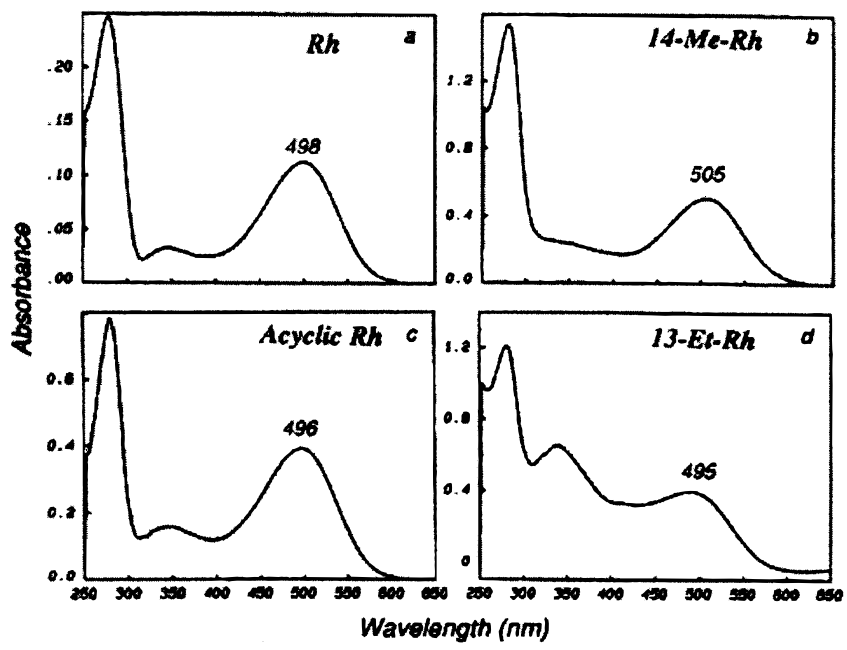

FIG. 2. UV/Vis spectra of the pigments: (a) rhodopsin (Rh), (b) 14-methylrhodopsin (14-MeRh), (c) acyclic rhodopsin (acyclic Rh), (d) 13-ethylrhodopsin (13-Et-Rh, which contained an impurity absorbing around $340 \mathrm{~nm}$ and hard to be washed off the Concanavalin A-Sepharose column during purification). 

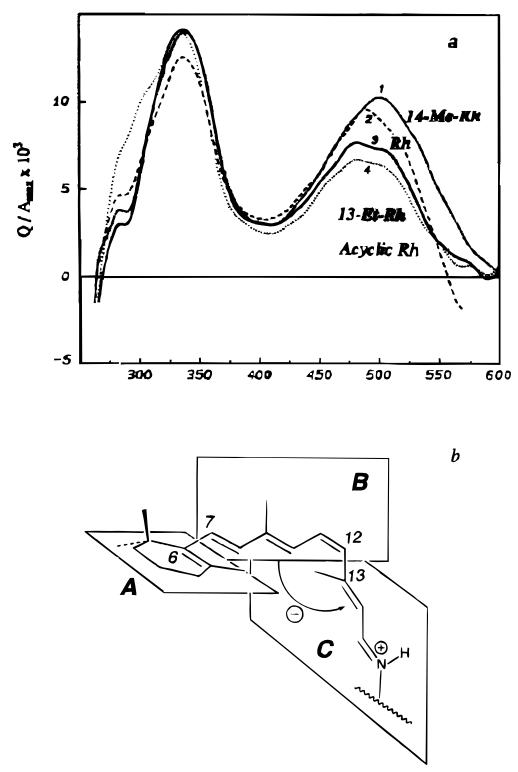

FIG. 3. (a) Circular dichroic spectra (CD) of rhodopsin and the pigments: (1) 14-methylrhodopsin; (2) rhodopsin; (3) 13-ethylrhodopsin; (4) Acyclic rhodopsin. (b) Retinal adopts a 6-s-cis and 12-s-trans conformation in rhodopsin. The distortions around 6-7 and 12-13 single induce the CD $\beta$-band (around $340 \mathrm{~nm}$ ) and $\mathrm{CD} \alpha$-band (around $480 \mathrm{~nm}$ ), respectively.

observed that a rhodopsin incorporating a retinal analog in which $\mathrm{B} / \mathrm{C}$ planes adopt a planar structure via a five-membered bridge between C-10 and 13-Me exhibit a negligible $480 \mathrm{~nm}$ CD band; similarly, the pigment formed from a retinal with planar $\mathrm{A} / \mathrm{B}$ conformation via a five-membered bridge between 5-Me and C-8 showed a weak $337 \mathrm{~nm}$ CD band. Based on these observations, the $\alpha$ - and $\beta$-bands have been ascribed to the distortions around 12-s and 6-s bonds, respectively $(32,33)$.

The overall simlarity of the UV/Vis (Fig. 2) and CD (Fig. 3a) spectra of all four rhodopsin pigments indicates that the conformations and electrostatic surroundings of the retinal chromophore within the protein chiral environment are similar. It is noteworthy that the $340 \mathrm{~nm} \mathrm{CD} \beta$-band of the pigment incorporating acyclic retinal 2 (Fig. 3a, curve 4) is similar to that of rhodopsin (Fig. 3a, curve 2), showing that the incomplete retinal cyclohexene ring still preserves the key elements to interact with the protein leading to a similar twist around the 6-s bond.

Certain differences in CD spectra are also noted. 13-Et-Rh has a smaller CD $\alpha$ band around $480 \mathrm{~nm}$ (Fig. 3a, curve 3), suggesting a less twisted 12-s bond as compared to rhodopsin. This is notable since a larger 12-s twist was expected as the steric hindrance between 10 and 13 position is larger in 11-cis 13-Et retinal than in native 11-cis retinal. Clearly factors other than the intrinsic properties of retinal, namely, the protein-retinal interactions, play important roles in determining the retinal chromophore conformation. 


\section{Stability against Heat and $\mathrm{NH}_{2} \mathrm{OH}$}

The stability of visual pigments against heat and $\mathrm{NH}_{2} \mathrm{OH}$, which reflect the overall stability of the chromophore and accessability of the Schiff base region to hydroxylamine (25), were measured by monitoring the $500 \mathrm{~nm}$ peak of purified pigment in $2 \%$ digitonin at $37^{\circ} \mathrm{C}$, and in $100 \mathrm{mM} \mathrm{NH}_{2} \mathrm{OH}$ at $0^{\circ} \mathrm{C}$, respectively.

The stability of 14-Me- $\mathrm{Rh}$ is drastically reduced, both thermally and against $\mathrm{NH}_{2} \mathrm{OH}$ (Figs. 4a and 4b); this can be accounted for, respectively, by increased steric congestion (21) and exposure of the protonated Schiff base linkage. In contrast, in the case of 13-Et-Rh, the increased steric congestion could be balanced by a tighter binding arising from increased hydrophobic interaction, thus leading to unchanged stability relative to Rh (Fig. 4a). However, as in the case of 14-Me-Rh, the protonated Schiff base linkage could be more exposed, leading to increased susceptibility to $\mathrm{NH}_{2} \mathrm{OH}$.

As shown in Fig. 4, acyclic Rh was slightly more stable than Rh against temperature and $\mathrm{NH}_{2} \mathrm{OH}$, which in addition to the faster binding of acyclic retinal 2, suggests a more energy-favorable chromophore-opsin interaction.

\section{Photoactivity}

The photoactivities of the pigments were evaluated by the PDE activity representing the entire photoactivation process, and the quantum efficiency of the primary photoactivation event, i.e., the retinal 11-ene isomerization. The results of these measurements are summarized in Table 1.

The very high quantum efficiency (0.67) of rhodopsin is dependent on the retinalreceptor interaction as well as the intrinsic properties of 11-cis retinal. It has been postulated that the steric interaction between the substituents at positions 10 and 13 in 11-cis retinal facilitates the rapid photoisomerization of the visual chromophore (34). Indeed, removal of this steric effect leads to a remarkable loss in quantum efficiency, reducing it to 0.30 for 13 -desmethyl $(13 \mathrm{dm})$ rhodopsin (35). Introduction of a methyl group at $\mathrm{C}-10$ in $13 \mathrm{dm}$ rhodopsin increases the quantum efficiency back
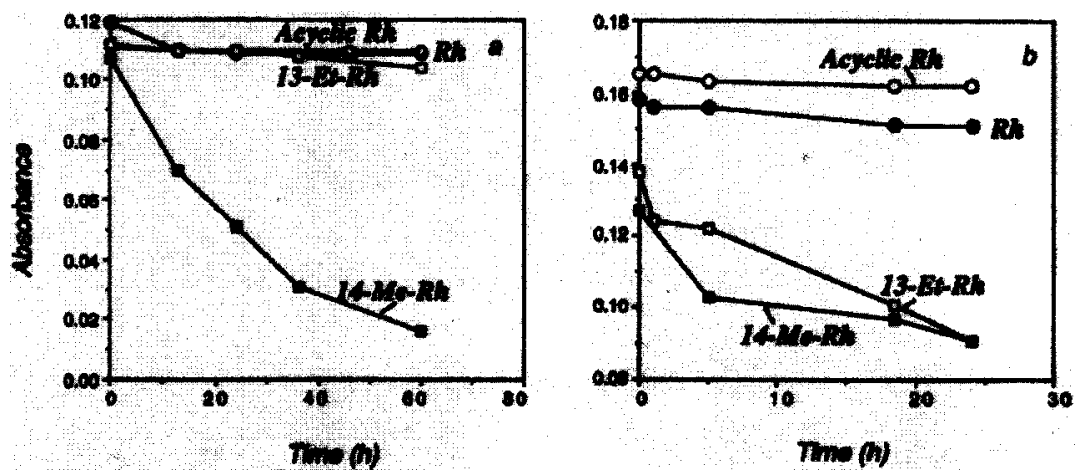

FIG. 4. The stability tests against (a) heat, $37^{\circ} \mathrm{C}$, and (b) $\mathrm{NH}_{2} \mathrm{OH}$. Both rhodopsin and the analogs were purified on Concanavalin A-Sepharose column in $2 \%$ digitonin with $100 \mathrm{mM}$ methyl $\alpha$-mannoside and the absorbance at the $\lambda_{\max }$ was monitored. For $\mathrm{NH}_{2} \mathrm{OH}$-stability test, rhodopsin, and each pigment samples contained $100 \mathrm{mM} \mathrm{NH}{ }_{2} \mathrm{OH}$. 
TABLE 1

UV/Vis Data, Quantum Efficiency, and Light-Dependent PDE Activity of Visual Pigments

\begin{tabular}{lcccc}
\hline & Rhodopsin & $\begin{array}{c}\text { Acyclic } \\
\text { Rhodopsin }\end{array}$ & $\begin{array}{c}\text { 14-Methyl } \\
\text { Rhodopsin }\end{array}$ & $\begin{array}{c}\text { 13-Ethyl } \\
\text { Rhodopsin }\end{array}$ \\
\hline$\varepsilon_{\max }(\mathrm{nm})$ & 40,600 & $45,200 \pm 600^{a}$ & $38,000 \pm 5000^{b}$ & $36,000 \pm 200^{a}$ \\
$\gamma_{\max }$ & 498 & 496 & 505 & 495 \\
Relative PDE Activity & $100 \%$ & $80 \%$ & $80 \%$ & $100 \%$ \\
Quantum Efficiency & $0.67^{c}$ & 0.48 & $0.55^{c}$ & 0.52 \\
\hline
\end{tabular}

${ }^{a}$ The $\varepsilon$ values at the absorption peaks of acyclic rhodopsin and 13-ethylrhodopsin were obtained by comparing the absorbance of regenerated pigments from 11-cis-retinal (1), 11-cis acyclic retinal (2), and 11-cis 13-ethylretinal (3), with the same opsin preparation in $10 \mathrm{mM}$ Chapso/10 mM Hepes (pH 7.0).

${ }^{b}$ Ref. (49); the quantum efficiency was recalculated based on the $\varepsilon$ and relative photosensitivity of rhodopsin and 14-methylrhodopsin at $560 \mathrm{~nm}$.

${ }^{c}$ Ref. (28).

to 0.59 (36). In our experiments, however, increasing the steric hindrance by replacing the 13-Me with a bulkier 13-Et reduces the quantum efficiency of the rhodopsin pigment to 0.52 , suggesting that other factors promoting the retinal photoisomerization, likely the correct protein-receptor interactions, have been disturbed by the extra bulk at 13-position.

Despite a lower quantum efficiency for the primary photoactivation, 13-EtRh exhibits a light-dependent PDE activity similar to native rhodopsin. It is possible that a 13 -Et is more efficient than a 13-Me for inducing the protein conformational changes following retinal isomerization, therefore offsetting the loss of quantum efficiency of the retinal isomerization to reach a similar overall photoactivity.

With acyclic Rh and 14-MeRh, the PDE activities and the quantum efficiencies are lower than with rhodopsin. It is not clear whether the low activities of PDE originate from low quantum efficiencies or a less active protein conformation at the Meta-II stage, or both. Nevertheless, an incomplete cyclohexene ring and an extra bulk at 14-position must disrupt the normal receptor-retinal interaction and, therefore, the efficiency of the photoactivation process.

\section{DISCUSSION}

The retinal binding pocket has been shown to be flexible to accommodate a variety of retinal analogs. It was reported in 1984 (37) that retinal analogs without the cyclohexene ring could still bind to opsin, while Liu and coworkers $(21,38)$ made semiquantitative comparisons of the binding rate of synthetic retinal analogs, among which acyclic retinal 2 showed efficient binding; this has been confirmed in our studies. 14-Methylretinal analog 3 (23) also binds with opsin to form stable rhodopsin pigments. Opsin can also incorporate retinal analogs containing 5- to 9-membered rings bridging $\mathrm{C}-10$ and $\mathrm{C}-13$ (15), thus showing that the binding domain in the vicinity of C-13 is relatively loose. The facile formation of 13-Et-Rh is thus not surprising.

It has been shown that although the protein binding cavity is flexible to accommodate structurally modified retinals, it frequently leads to less efficient photoactivation and/ or less stable pigments in the ground state $(21,39)$. This is also supported by the 
present finding that the stability and quantum efficiencies of 14-Me-Rh and 13-Et$\mathrm{Rh}$ are lower than those of rhodopsin; the light-dependent PDE activity of 14-Me$\mathrm{Rh}$ is also smaller.

The fast incorporation and high stability of acyclic retinal $\mathbf{2}$ suggests that deletion of part of the cyclohexene ring yields a flexible molecule where the chromophore-opsin interaction that could impede the binding process is absent. The photoactivity of the formed pigment, however, is lower, demonstrating that the ionone moiety with its hydrophobic methyl groups is essential for an efficient retinal $\rightarrow$ protein transmittal of structural changes induced by the chromophoric isomerization.

The changes in retinal chromophore and opsin 3D interactions trigerred by the 11cis to all-trans isomerization is central for activation of rhodopsin. Our photoaffinity labeling experiment using the ring-locked 11-cis retinal analog 5, which cross-linked cleanly to Trp-265 (in the middle of helix F, Fig. 5) has shown that in the ground state, the cyclohexene ring of the retinal chromophore is in close contact with helix F (13). In contrast, photoaffinity labeling of rhodopsin by Nakayama and Khorana using a photoisomerizable trifluoromethyldiazirene analog 6 led to two and six crosslinking sites on helices F and C, respectively(40), whereas in their site-directed spin labeling studies, Hubbell and Khorana and coworkers observed specific rigid-body motions of helices $\mathrm{C}$ and $\mathrm{F}$ upon photoactivation (41-44). Recent photocrosslinking studies performed sequentially at $-196^{\circ} \mathrm{C}$ to $0^{\circ} \mathrm{C}$ with the Batho-, Lumi-, Meta-I, and Meta-II Rh intermediates, using 11-cis 3-diazo-4-oxoretinal (diazoketo 5 without the bridging ethylene chain) have shown that the cross-linked amino acids in Batho$\mathrm{Rh}$ is Trp-265 (i.e., same as in resting state rhodopsin); after Lumi-Rh and subsequent intermediates, the diazoketo photolabile group binds exclusively to Ala-169 (in helix D). Namely, the transition of Batho-Rh to Lumi-Rh is accompanied by a flip-over of the cyclohexene moiety of the retinal chromophore so that the bridging changes from Trp-265 to Ala-169. This shows that helices C and D move, respectively, outward
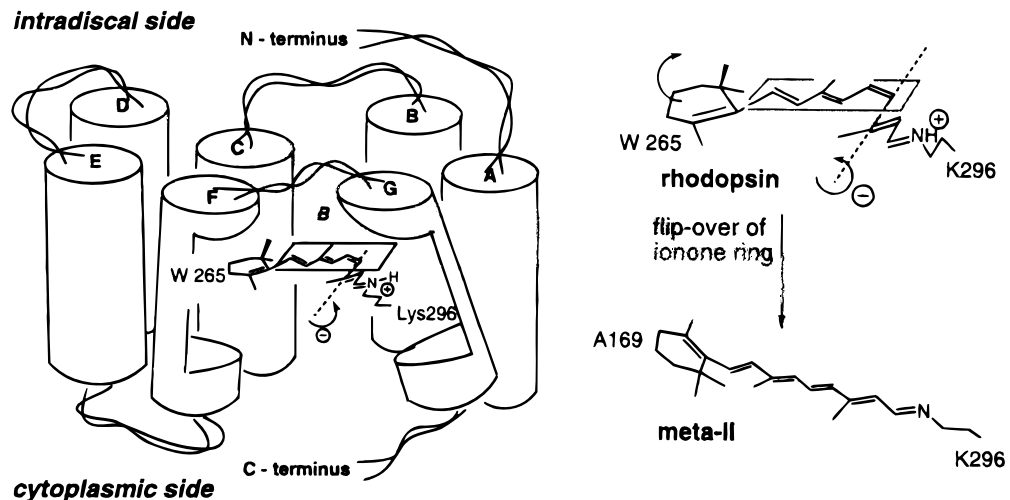

FIG. 5. The ionone ring (C-3) of the chromophore in the rhodpsin binding site is close to Trp-265 located around the middle of helix F; the negative absolute twist around the 12-s-bond is also depicted. In lumi-Rh and subsequent intermediates, the ionone ring flips over and C-3 becomes close to Ala- 169 in helix D. Protein conformational changes accompanying these changes activated the $G$ protein. 
and inward and it is these movements of helices and extramembrane loops that activate the $\mathrm{G}$ protein (M. Souto and B. Borhan, manuscript in preparation).

With flexible analog 2 the incomplete cyclohexene ring is in less tight contact with helices, and therefore the retinal/opsin interaction is inefficient in moving the helices for activation. This is in agreement with our recent studies (45) regarding the mechanism of transient dark activity of opsin induced by 11-cis 13 desmethyl retinal (13 $\mathrm{dm})$. Namely, it was shown that interaction of the retinal ring moiety with the opsin $\beta$-ionone binding domain (46-47) is required for the formation of the Meta II-like active species of the protein in the dark. In summary, the opsin/11-cis retinal complex has evolved into an ideal system, which is capable of converting photoenergy into Meta-II formation with high efficiency, critical for visual transduction.

\section{ACKNOWLEDGMENTS}

This study was supported by NIH Grants GM 34509 and GM 36564.

\section{REFERENCES}

1. Ottolenghi, M., and Sheves, M., (Eds.) (1995) Isr. J. Chem. 35 (Special issue of Photophysics and Photochemistry of Retinal Proteins).

2. Ovchinnikov, Y. A. (1982) FEBS Lett. 148, 179-191.

3. Hargrave, P. A., McDowell, J. H., Curtis, D. R., Wang, J. K., Juszczak, E., Fong, S. L., Rao, J. K., and Argos, P. (1983) Biophys. Struct. Mech. 9, 235-244.

4. Tang, L., Ebrey, T. G., and Subramaniam, S. (1995) Isr. J. Chem. 35, 193-209.

5. Wald, G. (1968) Nature 219, 800-807.

6. Stryer, L. (1991) J. Biol. Chem. 266, 10711-10714.

7. Chabre, M. (1985) Annu. Rev. Biophys. Biophys. Chem. 14, 331-360.

8. Hofmann, K. P. (1986) Photobiochem. Photobiophys. 13, 309-327.

9. Yoshizawa, T., and Shichida, Y. (1982) Methods Enzymol. 81, 333-354.

10. Yoshizawa, T., and Shichida, Y. (1982) Methods Enzymol. 81, 634-641.

11. Kliger, D., and Lewis, J. (1995) Isr. J. Chem. 35, 289-307.

12. Kochendoerfer, G., and Mathies, R. (1995) Isr. J. Chem. 35, 211-226.

13. Zhang, H., Lerro, K. A., Yamamoto, T., Lien, T. H., Sastry, L., Gawinowicz, M. A., and Nakanishi, K. (1994) J. Am. Chem. Soc. 116, 10165-10173.

14. Tan, Q., Lou, J., Borhan, B., Karnaukhova, E., Berova, N., and Nakanishi, K. (1997) Angew. Chem. Int. Eng. Ed. 36, 2089-2093.

15. Hu, S., Franklin, P. J., Wang, J., Ruiz Silva, B. E., Derguini, F., Nakanishi, K., and Chen, A. H. (1994) Biochemistry 33, 408-416.

16. Mizukami, T., Kandori, H., Shichida, Y., Chen, A. H., Derguini, F., Caldwell, C. G., Biffe, C. F., Nakanishi, K., and Yoshizawa, T. (1993) Proc. Natl. Acad. Sci. USA 90, 4072-4076.

17. Fukada, Y., Shichida, Y., Yoshizawa, T., Ito, M., Kodama, A., and Tsukida, K. (1984) Biochemistry 23, 5826-5832.

18. De Grip, W. J., Van Oostrum, J., Bovee-Geurts, P. H. M., Van der Steen, R., Van Amsterdam, L. J. P., Groesbeek, M., and Lugtenburg, J. (1990) Eur. J. Biochem. 191, 211-220.

19. Bhattacharya, S., Ridge, K. D., Knox, B. E., and Khorana, H. G. (1992) J. Biol. Chem. 267, 6763-6769.

20. Nakanishi, K. (1991) Pure Appl. Chem. 63, 161-170.

21. Liu, R. S. H., and Asato, A. E. (1990) in Chemistry and Biology of Synyhetic Retinoids (Dawson, M. I., and Okamura, W. H., Eds.), pp. 51-75, CRC Press, Cleveland, OH.

22. Nakanishi, K. (1985) Pure Appl. Chem. 57, 769-776.

23. Chan, W. K., Nakanishi, K., Ebrey, T. G., and Honig, B. (1974) J. Am. Chem. Soc. 96, 3642-3644.

24. Papermaster, D. S. (1982) Methods Enzymol. 81, 49-52.

25. De Grip, W. J. (1982) Methods Enzymol. 81, 256-265.

26. Cusanovich, M. A. (1982) Methods Enzymol. 81, 443-447.

27. Dixon, S. F., and Cooper, A. (1987) Photochem Photobiol 46, 115-119. 
28. Dartnall, H. J. A. (1972) in Sensory Physiology (Dartnall, H. J. A., Ed.), Vol. VII/1, pp. 122-145.

29. Liebman, P. A., and Ivanczsuk, A. Y. (1982) Methods Enzymol. 81, 532-542.

30. Kropf, A. K., Whittenberger, B. P., Goff, S. P., and Waggoner, A. S. (1973) Exp. Eye Res. 17, 591-606.

31. van der Steen, R., Groesbeek, M., van Amsterdam, L. J. P., Lugtenburg, J., van Oostrum, J., and De Grip, W. J. (1989) Recl. Trav. Chim. Pays-Bas. 108, 20-27.

32. Ito, M., Kodama, A., Tsukida, K., Fudaka, Y., Shichida, Y., and Yoshizawa, T. (1982) Chem. Pharm. Bull. 30, 1913-1916.

33. Ito, M., Katsuta, Y., Imamoto, Y., Shichida, Y., and Yoshizawa, T. (1992) Photochem. Photobiol. 56, 915-919.

34. Peteanu, L. A., Schoenlein, R. W., Wang, Q., Mathies, R. A., and Shank, C. V. (1993) Proc. Natl. Acad. Sci. USA 90, 11762-11766.

35. Ternieden, S., and Gartner, W. (1996) J. Photochem. Photobiol. B. 33, 83-86.

36. Koch, D., and Gartner, W. (1997) Photochem. Photobiol. 65, 181-186.

37. Crouch, R., Nodes, B. R., Perlman, J. I., Pepperberg, D. R., Akita, H., and Nakanishi, K. (1984) Invest. Ophthalmol. Vis. Sci. 25, 419-428.

38. Liu, R. S. H., Asato, A. E., Denny, M., and Mead, D. (1984) J. Am. Chem. Soc. 106, 8298-8300.

39. Kochendoerfer, G. G., Verdegem, P. J., van der Hoef, I., Lugtenburg, J., and Mathies, R. A. (1996) Biochemistry 35, 16230-16240.

40. Nakayama, T. A., and Khorana, H. G. (1990) J. Biol. Chem. 265, 15762-15769.

41. Altenbach, C., Yang, K., Farrens, D. L., Farahbakhsh, Z. T., Khorana, H. G., and Hubbell, W. L. (1996) Biochemistry 35, 12470-12478.

42. Farahbakhsh, Z. T., Ridge, K. D., Khorana, H. G., and Hubbell, W. L. (1995) Biochemistry 34, 8812-8819.

43. Yang, K., Farrens, D. L., Altenbach, C., Farahbakhsh, Z. T., Hubbell, W. L., and Khorana, H. G. (1996) Biochemistry 35, 14040-14046.

44. Farrens, D. L., Altenbach, C., Yang, K., Hubbell, W. L., and Khorana, H. G. (1996) Science 274, 768-770.

45. Tan, Q., Nakanishi, K., and Crouch, R. K., (1998) J. Am. Chem. Soc. 120, 12357-12358.

46. Matsumoto, H., and Yoshizawa, T. (1975) Nature 258, 523-526.

47. Jäger, S., Palczewski, K., and Hofmann, K. P. (1996) Biochemistry 35, 2901-2929. 